\title{
A cultura empreendedora nos discursos sobre a juventude
}

Julia Salgado

Resumo: Neste artigo examino alguns discursos midiáticos que promovem aquilo que chamei de cultura empreendedora. Partindo da análise comparativa de duas séries televisivas voltadas para o público jovem em temporalidades distintas, busco examinar algumas retóricas midiáticas que celebram o empreendedorismo juvenil como resposta às demandas por sucesso pessoal e como solução ao problema do desemprego estrutural. Antes, porém, faço uma contextualização do ambiente social que se construiu a partir da emergência de uma racionalidade neoliberal, procurando, com isso, compreender a relação da cultura empreendedora com lógicas sistêmicas mais amplas e dominantes.

Palavras-chave: empreendedorismo; neoliberalismo; educação; juventude; mídia

Abstract: The entrepreneurial culture in discourses about youth - In this article I examine some media discourses that promote what I call entrepreneurial culture. Based on a comparative analysis of two television series for young audiences in different temporalities, I seek to examine some media rhetorics that celebrate youth entrepreneurship as a response to the demands for personal success and as a solution to the problem of structural unemployment. First, however, I contextualize the social environment that was built from the emergence of a neoliberal rationality, thereby seeking to understand the relationship between entrepreneurial culture and broader and more dominant systemic logics.

Keywords: entrepreneurship; neoliberalism; education; youth; media

\section{Introdução}

O ano de 1992 foi emblemático para o Brasil: ficou marcado na história como data em que milhares de jovens estudantes - os caras pintadas - mobilizaram a nação pela deposição do poder de um presidente da república cujo projeto de governo intencionava alinhar o país às normatividades neoliberais de gestão. Liberação fiscal e financeira, abertura do mercado nacional à livre concorrência internacional e desestatização das empresas nacionais foram algumas de suas ações. $E$, nesse mesmo ano em que os jovens pintaram o rosto e foram às ruas, um produto cultural voltado para eles foi lançado com 
espantoso sucesso: Confissões de adolescente. O livro, que depois virou peça teatral, série de TV e filme, tem seu enredo baseado em vivências, dilemas e práticas corriqueiras de quatro jovens irmãs na ali referida "perturbada adolescência". Assuntos até então muitas vezes interditos para esse público - como sexo, drogas e política - viram mote para capítulos, atos e episódios. O seriado, que foi ao ar na TV Cultura em 1994, conta a história das quatro irmãs que, órfãs ou abandonadas pelas respectivas mães, vivem com o pai na zona sul do Rio de Janeiro. Genericamente, aborda as mais diversas questões cotidianas: os relacionamentos, as sociabilidades, as afetividades juvenis.

Quinze anos depois, a realidade política e econômica brasileira é diversa: já totalmente integrado ao sistema financeiro mundial, o país conta com um livre mercado no qual produtos, serviços e empresas de todo o planeta concorrem pela preferência do agora "empoderado consumidor brasileiro". Nesse cenário, outro produto midiático voltado para os adolescentes é lançado: Ger@l.com. A internet e as correlatas ferramentas de comunicação fornecem a base sobre a qual a narrativa do programa se desenvolve e em que as questões sobre juventude florescem. A minissérie da Rede Globo, exibida entre 2009 e 2010, faz uso de uma linguagem híbrida entre realidade e ficção ao tratar das aventuras de cinco adolescentes de treze anos que produzem um site de compartilhamento de músicas, fotos, vídeos, games: o LigaGer@l.com. As peripécias da turma ganham especial contorno quando entra em cena a real banda teen WWW ${ }^{1}$ buscando um lugar para ensaiar e gravar seu primeiro clipe. Objetivo: postá-lo na internet, aumentando assim as chances de visibilidade e sucesso da banda. Diferentemente do que ocorre em Confissões, há aqui uma quase total ausência de tópicos ditos "polêmicos"; o que domina são temas ligados à tecnologia (de comunicação e informação), ao consumo e à cultura pop.

A escolha das duas séries televisivas como ponto de partida para a análise proposta se justifica não apenas por se tratar de representações midiáticas da juventude ${ }^{2}$ em duas temporalidades diversas, mas porque possibilita a comparação de temas e abordagens julgados pertinentes por seus enunciadores, seja em meados da década de 1990, seja nos dias atuais. Justifica-se também por serem produtos que, embora apenas representações ${ }^{3}$, dialogam com assuntos e práticas familiares à vida corriqueira dessa adolescência específica, almejando assim um status de maior "realidade".

Neste artigo, portanto, proponho o exame de algumas articulações discursivas capazes de promover a cultura empreendedora como solução benfazeja aos mais variados males contemporâneos - da demanda por realização e sucesso pessoais ao desemprego estrutural.

1 A banda WWW existe desde 2006 e seu nome tem origem no sobrenome de seus integrantes, Werneck. Não deixa, porém, de ser interessante a ligação entre o nome e a sequência de letras mais digitada pela juventude hoje.

2 A adolescência específica à qual faremos referência é a apresentada nas duas séries: jovens brancos, entre dez e dezenove anos, de classe média alta e moradores da cidade do Rio de Janeiro.

3 Entendendo uma representação como resultado da ação humana (neste caso, os construtores do discurso midiático) sobre as imagens do mundo (o vasto campo de percepção do universo), reduzindo-as, ampliando-as, delas eliminando o que não lhes interessa ou adicionando o que lhes seja vantajoso, importa compreender o porquê das escolhas de como representar essas juventudes. 
Norteada pela abordagem foucaultiana, que entende os diversos discursos que circulam pelo tecido social como incansáveis operários, constantemente construindo sentidos, edificando representações e operando naturalizações, recorro nesta análise não apenas aos produtos acima descritos, mas também a outros campos discursivos impregnados pelos valores do empreendedorismo: desde reportagens em revistas de grande circulação nacional até documentos legislativos. O caráter diversificado e assistemático do corpus apresentado não visa servir como simples exemplificação da hipótese levantada - a de que está em curso um processo de subjetivação que privilegia traços empreendedores entre os jovens -, mas sim demonstrar a amplitude da retórica empreendedora nos discursos sociais. Antes, porém, de examinar o modo como o empreendedorismo é inserido nos discursos sobre a juventude, cabe traçar um panorama do contexto socioeconômico conhecido como neoliberalismo.

\section{Liberalismo e neoliberalismo}

Em Nascimento da biopolítica, Michel Foucault se propôs a estudar "a arte de governar, isto é, a maneira pensada de governar o melhor possível e também, ao mesmo tempo, a reflexão sobre a melhor maneira possível de governar" (FOUCAULT, 2008, p. 4). Essa nova arte de governar, diferentemente da razão de Estado, se caracterizaria pela limitação no exercício do poder de governar. Foucault mostra como esse novo formato do Estado - o liberalismo - é, mais do que doador de uma incondicional liberdade, acima de tudo seu consumidor: para que ele de fato funcione em todos os âmbitos (econômico, político, social), é preciso que sejam garantidas certas liberdades como liberdade de mercado, propriedade, circulação etc. Será, portanto, será função dessa nova forma de governar produzir, organizar e gerenciar as liberdades sociais.

O liberalismo, assim, denota uma governamentalidade que exige, ao mesmo tempo, a produção e a contenção da liberdade: é preciso produzi-la e estimulá-la, mas também limitá-la através de controles, coerções e obrigações. Adequar o sujeito à nova sociedade que emerge significa educá-lo e adestrá-lo ao uso e ao consumo da sua liberdade, assim como ao respeito à liberdade alheia. A tarefa é não permitir que uma liberdade específica prejudique as demais, o que equivale a dizer que se buscava uma conjugação entre liberdade e segurança. Para isso, tradicionais e modernas instituições são incumbidas de educar os indivíduos para o exercício das "liberdades da cidadania". Em Powers of freedom (1999), Nikolas Rose mostra que tais instituições ensinariam os próprios indivíduos a regular a sua conduta e a dos outros, criando assim uma rede de visibilidades em que regras e normas públicas se imporiam sobre as condutas pessoais. Além do próprio Estado, outros organismos são indispensáveis para o bom funcionamento de uma gestão liberal: a escola e o exército, a família e as fábricas e, não menos importante, o próprio espaço público. São esses espaços de ação e socialização dos sujeitos que passam a agir sobre 
seus corpos e suas mentes, normalizando, racionalizando, regularizando ou sensibilizando as condutas humanas na direção daquilo que se acreditava ser uma conduta cívica ideal para o alcance do bem-estar coletivo e da prosperidade geral.

Mas o Estado onipresente e ativamente atuante na vida dos sujeitos foi, aos poucos, sendo substituído por uma forma de governar ainda mais liberal e frugal: o liberalismo, que prezava por um bem-estar coletivo conquistado a partir de uma governamentalidade atuante (ROSE, 1999), evoluiu para um modelo mais economicamente eficiente e menos regulatório: o neoliberalismo. Este será entendido aqui não apenas sob prismas econômicos, que preveem um Estado menos intervencionista nos negócios do agora livre mercado. Interessa, em especial, compreender que essa nova lógica de livre circulação de capitais, pessoas e informações necessita de transformações paralelas nos valores e nas práticas do indivíduo, constrangido a adaptar-se ao novo modelo neoliberal. Sobre esse sujeito contemporâneo incidem novas racionalidades e práticas de governo da conduta que prezam não apenas liberdade, mas também autonomia, performance, flexibilização, empreendedorismo e responsabilização individuais.

Aderindo à lógica neoliberal que simultaneamente legitima o mercado e deslegitima o social (COULDRY, 2008), o Estado estaria cada vez menos presente (de forma efetiva e eficiente) na vida de cidadãos, que passam a obter diretrizes e influências de outras instituições e organismos, notadamente as grandes empresas transnacionais, os grupos midiáticos e as novas redes autônomas de solidariedade. Se antes as referências comportamentais, os estilos de vida e as coerções que regulavam modos de agir provinham principalmente do Estado, da escola e da família, hoje é mais provável que marcas, slogans, referências grupais e produtos midiáticos das mais variadas empresas atuem com incidência na mente e no corpo dos sujeitos contemporâneos.

Nessa maratona autônoma e desroteirizada por melhores modos de ser e existir, um grupo parece se destacar: os jovens. Nascidos em meio aos desenvolvimentos do sistema neoliberal e às revoluções tecnológicas, os jovens que hoje têm treze, quinze ou vinte anos nunca tenham provavelmente vivenciado uma sociedade disciplinar como aquela analisada por Foucault, na qual as liberdades produzidas coexistiam com pungentes coerções e restrições. Se, por um lado, esse modo de vida desregulamentado e carente de orientações pode parecer penoso e árduo para os mais velhos - em teoria acostumados às normatividades e às garantias da modernidade -, não será, para os mais jovens, um caminho menos amargo. Isso aparece, algumas vezes de maneira clara, outras de modo sutil, na análise das representações contidas nas séries aqui estudadas.

O intervalo de tempo entre as duas séries, apesar de pequeno se pensado em termos históricos, é suficientemente relevante em termos de distanciamento de valores - em especial naquilo que se refere à adequação a um mundo mais desregulamentado e desprovido de modernas instituições de controle. Vale relembrar, como apontado na introdução, que Confissões foi uma série criada com base num diário íntimo escrito no florescer da década 
de 1990, quando o Brasil ainda passava por um lento processo de redemocratização, abertura e adesão ao mundo globalizado e neoliberal. Portanto, práticas e éticas sociais particulares ligadas a uma mentalidade ainda paternalista e regulamentada estão ali tão (ou mais) presentes quanto um embrionário discurso neoliberal, este sim totalmente presente e dominante no final da década 2000 - seja na outra série analisada, Ger@l.com, seja nos demais materiais examinados.

\section{Formação e empreendedorismo}

Uma importante descontinuidade é percebida na análise das duas séries: diz respeito às expectativas e às elucubrações sobre o futuro dos jovens, mais especificamente sobre os caminhos pelos quais se espera (ou se aceita) que um adolescente atinja sua maturidade e sua independência. Em Confissões, o estudo e a formação acadêmica são vistos como único caminho aceitável para que um jovem de classe média alta consiga conquistar sucesso profissional e financeiro e, assim, tornar-se um adulto responsável e autônomo. Em diferentes episódios, as personagens Carol (treze anos) e Bárbara (dezessete anos) questionam o porquê de ter de acabar o colégio ou fazer vestibular, sugerindo uma possível escapatória via ocupações que prescindam de uma formação acadêmica mais avançada, proposta esta que é prontamente recusada por seu pai. Este, ao ouvir de Bárbara o questionamento "Por que eu tenho de fazer vestibular?", responde de pronto: "Como por quê? Minha filha, você não vai ter papai para te sustentar a vida toda. As coisas não estão mole [sic], a vida não é uma mesa de doce. Você já parou para pensar como é que você vai se sustentar?" ("O que vou ser quando crescer", 5/9/1994). Em seguida, o pai sugere que a filha, indecisa, faça faculdade de direito e "siga a profissão do papai".

As concepções de sucesso financeiro e realização profissional ainda são, ali, atadas à noção hegemônica da instituição escolar como locus de formação de um corpo frágil e despreparado, que precisa ser moldado, construído e adaptado à realidade que vai enfrentar adiante. Assim, a série constrói um ambiente no qual o foco principal das jovens deve ser o estudo: ir à escola ou à faculdade, estudar para uma prova, ter de fazer vestibular são, mais do que elementos secundários da narrativa, o pano de fundo mesmo das aventuras juvenis. A obrigatoriedade do estudo é algumas vezes questionada, como no episódio "A lei de Paulo" (28/11/1994), quando o pai das jovens restringe suas mesadas. Sem considerar a possibilidade de ficar sem dinheiro ("mas como a gente vai ao cinema?", "como vou comprar o ingresso do show?", "você sabe quanto está custando o hambúrguer da escola?"), as jovens se veem obrigadas a trabalhar para poder sustentar seus consumos. Tal empreendedorismo, no entanto, é apresentado como consequência de uma contingência (o estar sem mesada), e não como ato voluntário das jovens.

Ger@/.com apresenta uma perspectiva diferente: os sucessos profissional e financeiro são vistos como alcançáveis não exclusivamente pelo estudo e pela formação acadêmica, mas também por uma conjugação de talento, dedicação e empreendedorismo. A trama 
se desenvolve com a tentativa dos jovens de tornar possível o sonho de notoriedade da banda WWW. Para eles, o sucesso iminente está menos sujeito às "aulas tradicionais" a que assistem na escola do que às aulas de canto, piano ou guitarra; à frequência e dedicação em seus ensaios; à divulgação e promoção que fazem de suas músicas e clipes na internet. Outro personagem da trama que mostra recorrente fixação por sucesso, fortuna e notoriedade através de um caminho menos ortodoxo é Júnior, jovem de treze anos absorvido em seu objetivo de produzir, gravar e veicular o "maior vídeo viral de todos os tempos". É curioso quando ele se compara a George Lucas, fazendo referência à similaridade do descrédito que ele recebe hoje de seus amigos e do suposto descrédito que o cineasta norte-americano também teria recebido em seu início de carreira. A atitude de "acreditar em si", a despeito do descrédito alheio, é digna das edificantes lições das literaturas de management pessoal e do "jornalismo de autoajuda" (FREIRE FILHO, 2011) que proliferam mundo afora.

Nessa nova arquitetura da edificação profissional juvenil é possível perceber a relação com atuais discursos empresariais que, à semelhança do léxico artístico e de resistência de décadas passadas, pregam pela exaltação de flexibilidade, criatividade, dinamismo e autonomia (BOLTANSKI e CHIAPELLO, 2009). A mistura desses ingredientes em uma atividade produtiva pode ser percebida nas diversas cenas da série da Rede Globo em que os jovens aparecem produzindo conteúdo, fazendo manutenção e atualizando o site LigaGer@l. com. Os adolescentes são constantemente vistos com suas "ferramentas de trabalho" (celulares, computadores, câmeras) a tiracolo, já que os momentos produtivos se misturam aos momentos de lazer, em uma rotina em que as grandes ideias não têm hora para surgir e ser implementadas. Não sem um pouco de desânimo percebe-se que a exaltação do lado flexível ou sempre à disposição dos jovens não é contrabalanceada com alertas sobre seus riscos correlatos, como a fadiga, a ansiedade, a depressão (EHRENBERG, 2010).

É importante esclarecer que em nenhum momento há, na série, a deslegitimação do estudo acadêmico como importante via para a formação profissional - via esta, cada vez mais longa e determinante nas condições de empregabilidade (BOLTANSKI e CHIAPELLO, 2009). Ao contrário, o estudo é reconhecido como importante caminho de crescimento e formação individual, como mostra a análise dos quase quinhentos comentários de jovens estudantes sobre a pergunta lançada no site de Ger@l.com: "Escola pra quê?"”. Grande parte dos adolescentes vê a escola sob a perspectiva do caminho fundamental para a formação daqueles com grandes pretensões futuras. ${ }^{5}$ Dessa forma, não se trata de tirar o estudo e o aprendizado formais como meios para a obtenção de reconhecimento e dinheiro, mas

4 O mero questionamento sobre a finalidade da escola já diz bastante sobre esses jovens que, mesmo ainda tendo a obrigação de frequentar instituições de ensino, já são encenados como produtivos e lucrativos. Disponível em: <http://tvglobo.geral.globo.com/geralzona/2009/12/14/escola-pra-que/>. Acesso em: 2 abr. 2010.

5 Comentários do link anterior, sem correção de ortografia: "eu acho a escola fundamental por que se nao como iriamos aprender mas nao nego que orrivel quando tem prova surpresa e cai coisas que agenta nao sabe" (Eduarda, 16/12/2009); "Escola para mim vem na cabeça estudar para ter um futuro melhor financeiramente por isso q sou muito estudioso e luto por um futuro brilhante para mim" (Tamara, 16/12/2009); "Escola pra ter um futuro ótimo e, além disso, obrigado a qm estudou muito e criou a net" (She, 17/12/2009). 
sim de acrescentar fatores que antes eram pouco demandados à maioria das profissões e hoje se configuram essenciais para a formação de um corpo não mais dócil e prosaico, mas acima de tudo criativo, autônomo e extraordinário.

Nessa renovada equação do aprendizado contemporâneo um conceito relativamente recente ganha visibilidade: o empreendedorismo. A relação entre os discursos midiáticos aqui analisados e a cultura empreendedora permeia diversas áreas da vida dos jovens encenados: de suas relações sociais aos seus projetos de vida, de seus bens de consumo às suas ações de cidadania. Mas, afinal, o que é a cultura empreendedora? Sobre quais bases (ou diante de quais problemas) ela surge na contemporaneidade e quais lógicas justificam sua popularidade no universo juvenil?

Para responder a essas questões recorro a textos que adotam caminhos multidisciplinares (passando pela economia, educação e sociologia), na tentativa de compreender um fenômeno historicamente recente e com pouca literatura crítica no Brasil. O educador Sylvio Costa (2009) argumenta que um dos caminhos para compreender o nascimento da cultura empreendedora está na Escola de Chicago, mais especificamente na ali difundida teoria do capital humano. Na década de 1960, a teoria defendia que a maior fonte de capital dos indivíduos não era mais a força de seu trabalho ou a habilidade mecânica de exercer tarefas, funções agora executáveis por máquinas. Prevendo não apenas o avanço tecnológico, mas também as desregulamentações do universo corporativo, os economistas de Chicago apontaram que o novo investimento do indivíduo seria seu conhecimento acumulado: o conjunto de habilidades, capacidades e destrezas que lhe permite atuar em diversas áreas e sob múltiplos cenários, sendo capaz inclusive de propor novas ideias e soluções eficazes aos mais variados problemas da empresa. Não mais apenas produtivo, o ser-empreendedor é, acima de tudo, proativo, inovador, oportunista e, claro, lucrativo. "O indivíduo moderno, a que se qualificava como sujeito de direitos, transmuta-se, assim, num indivíduo-microempresa: Você S/A" (COSTA, 2009, p. 177).

Costa argumenta que, diante da necessidade mercadológica de transformar os sujeitos modernos em indivíduos-microempresa, uma nova governamentalidade passa a agir, regulando e naturalizando aspectos tipicamente empresariais (gestão, liderança, marketing, avaliação de riscos e oportunidades) nas esferas social e privada. Essa naturalização de modos de ser, agir, pensar e situar-se no mundo baseados em princípios de competitividade (Rose, 1998), performatividade (Ball, 2004), lucratividade e sucesso encontra ressonância na educação básica e estendida, na mídia e nas literaturas empresarial e de autoajuda, formando assim uma cultura empreendedora que atinge, em maior ou menor proporção, adultos, jovens e crianças. Diante da impossibilidade de examinar todas as esferas sociais em que o discurso do empreendedorismo se alojou (ou vem se alojando), foco meus esforços nas áreas com maior interface com os jovens: a educação e a mídia. 
Na educação, discute-se a relevância de um aprendizado científico-cultural tradicional nos dias de hoje, questionando se tal foco ainda estaria de acordo com um mundo no qual a oferta de empregos formais não acompanha o crescimento da entrada de jovens no mercado de trabalho. Assim são propostas abordagens que estimulem o lado criativo, inovador e flexível dos jovens, ensinando-os a "aprender a aprender". Enquanto o ensino tradicional é baseado "numa ciência lógica e racional, em que o processo de ensino centra-se na figura do professor como único detentor do saber, cabendo aos alunos apenas a assimilação de conhecimentos sistematizados", surgem "novas propostas pedagógicas centradas no aluno como agente ativo no processo ensino e aprendizagem" (DAVID et ali, 2001, p. 2).

De fato, a preocupação em prover aos jovens uma formação menos clássica e mais voltada às atuais especificidades do mercado de trabalho não fica circunscrita apenas às escolas privadas, que têm capacidade (estrutural e financeira) de incluir matérias atinentes com a cultura empreendedora em sua grade curricular. O pequeno município de Rio do Sul, em Santa Catarina, aprovou, em 2010, lei ordinária que institui como obrigatória a disciplina empreendedorismo na grade curricular do ensino fundamental (do sexto ao nono anos). Segundo o artigo sexto dessa lei, a disciplina deverá conter, entre outras coisas:

I - noções de empreendedorismo, plano de negócios e empreendedorismo rural; II - identificação de oportunidades, preparação para o mercado de trabalho e primeiro emprego; III - construção de competências profissionais, habilidades sociais e marketing pessoal; IV - motivação para superação de obstáculos, estímulo à criatividade, formando alunos autônomos, éticos e responsáveis (Lei Ordinária de Rio do Sul-SC, n. 4991 de 21/5/2010).

Superar obstáculos, desenvolver habilidades sociais e construir um marketing pessoal - assim como demanda a lei supracitada - certamente faz parte da seara discursiva das centenas de cursos de extensão, livros (de management ou autoajuda) e palestras motivacionais, hoje em abundância em todo o mundo. Mas o que se pretende discutir aqui é a apropriação da lógica empreendedora (na qual a individualidade e a autossuficiência são imperativos irrefutáveis) pelas políticas - públicas e privadas - de ensino básico. Ou seja, o que (ou ainda, por que) justificaria o massivo incentivo para que crianças e jovens se desenvolvam, desde muito cedo, segundo uma mentalidade empreendedora?

A resposta mais recorrente está formulada em termos econômicos. Diante do enorme desemprego estrutural, que atinge com maior veemência os jovens entre quinze e 24 anos (POCHMANN, 2007), a saída encontrada por políticos, educadores e consultores públicos é estimular os jovens a desenvolverem projetos de vida nos quais eles próprios poderiam encontrar alternativas ao desemprego, através da criação de pequenos negócios capazes de gerar novos empregos. Assim, projetos como Jovem Empreendedor ${ }^{6}$ e Pedagogia

6 Projeto do governo federal em parceria com o Sebrae que concede empréstimos a empreendedores de até 24 anos. Disponível em: <http://portal.mte.gov.br/codefat/resolucao-n-339-de-10-07-2003.htm>. Acesso em: 2 jan. 2013. 
Empreendedora ${ }^{7}$ servem de estímulo ao jovem que agora é levado a acreditar que reside nele - através de seu "espírito empreendedor" (DOLABELA, 2003) - o potencial e as ferramentas para fugir do desemprego estrutural. Seguindo a linha de raciocínio neoliberal, que transfere responsabilidades institucionais para os próprios indivíduos (constitucionalmente, o acesso ao emprego é um dos direitos e garantias fundamentais de todo brasileiro ${ }^{8}$ ), a educadora Jane Drewinski se pergunta se projetos como os supracitados,

que enfatizam a estratégia educacional para desenvolver no indivíduo a capacidade de criar suas próprias oportunidades de emprego ou geração de renda [na verdade] deslocam o eixo da solução do desemprego das condições econômicas para o indivíduo. Em outros termos, é preciso investigar em que medida essas propostas deslocam da sociedade para o indivíduo a responsabilidade pelo combate ao desemprego (DREWINSKI, 2009, p. 16).

Na mídia tem-se tornado usuais discursos que ligam juventude ao empreendedorismo. Mais recentemente, vemos a proliferação de reportagens que, ao abordar o tema jovens empreendedores, valorizam não apenas o seu "espírito empreendedor", mas também os usos que os jovens fazem da tecnologia como atalho de conquista de novos mercados. A retórica das reportagens normalmente obedece ao mesmo raciocínio: nascidos em meio às tecnologias, eles conseguem enxergar em suas funcionalidades soluções para os mais variados problemas (ou incitações para novas demandas), propondo algo que os mais velhos, com suas mentes seriais, não encontram. Segundo essas reportagens os jovens seriam, entre outros adjetivos, inovadores, interessados, proativos, curiosos, autodidatas, criativos e ágeis.

Em 10 de novembro de 2010 a revista Veja Rio dedica uma página inteira à história de Pedro Henrique, menino de catorze anos que cria aplicativos para iPhone e já trabalha, três vezes por semana, como consultor em uma empresa de tecnologia. O empreendedorismo, aqui, é individual: ele não fundou uma nova empresa, não criou empregos e não ajudou sua comunidade local. Seus feitos são pessoais, assim como seus lucros. Não obstante, Veja Rio celebra a desenvoltura de mais um "prodígio da geração digital":

Seu corpo de menino esconde um raciocínio veloz e um jeito de falar tão articulado que chega a causar inveja. Objetivo, metódico e ponderado, ele tem ideias estranhamente maduras para sua idade. E a cada dia tenta realizá-las. Sozinho, já criou cerca de trinta aplicativos para os aparelhos da companhia americana Apple, além de ferramentas para a web. O que fez mais sucesso já foi baixado por quase 10000 usuários ao redor do mundo (VEJA Rio, 10/11/2010).

7 "A Pedagogia Empreendedora é uma estratégia didática para o desenvolvimento da capacidade empreendedora de alunos da educação infantil até o nível médio" (DOLABELA, 2003, p. 55).

8 No rol dos Direitos Sociais do artigo $6^{\circ}$ da Constituição Brasileira está o direito ao trabalho, sendo correto, portanto, dizer que este é um direito que deveria ser resguardado pelo Estado. 
Em seguida a reportagem avalia seu desempenho escolar, concluindo, nas entrelinhas, que ser um bom aluno no colégio não é a única via de promoção ao sucesso: nesse caso, a dedicação à computação legitima-se sobre os estudos. "Nas horas de lazer, porém, as diferenças em relação aos coleguinhas aparecem em cores mais vivas. Enquanto eles jogam videogame, futebol e gostam de colecionar figurinhas, Pedro Henrique adora ficar... no computador" (idem ibidem).

A revista Época de 22 de novembro de 2010 dedicou a capa e a reportagem principal aos "novos milionários da internet", jovens que usaram uma combinação de ousadia, oportunismo e conhecimentos da web para fundar empresas com pretensões milionárias. A grande ideia, segundo Época, foi unir empreendedorismo e inovação tecnológica:

Surge no Brasil uma nova geração de empreendedores da internet. Os mais bem-sucedidos deles já estão faturando alguns milhões de reais. São jovens, nascidos nos anos 80, mas formam uma "geração" por outros motivos mais importantes. Como seus antecessores, eles largaram a segurança de empregos promissores e arriscaram suas economias num negócio próprio (ÉPOCA, 22/11/2010).

A predisposição ao risco - como a capacidade de "largar a segurança de um emprego estável e promissor" - é recorrentemente exaltada nas narrativas, subliminar ou explicitamente. Contrapondo o "heroísmo de empreender" à "acomodação de empregos estáveis", o emprego público torna-se vilão no discurso empreendedor, chegando a ser avaliado em termos de desperdício: "O país não pode encaminhar a sua nata intelectual para o serviço público inoperante", defende Fernando Dolabela, guru em educação empreendedora, para a Veja Online de 2 de dezembro de 2009. Os jovens que se dedicam à acumulação de conhecimento necessária à aprovação em concursos estariam, assim, não apenas empregando mal seu tempo, mas, de modo mais abrangente, fazendo um desserviço a todo país. É o que defende, em artigo publicado no jornal Valor Econômico, Ronaldo Mota, secretário do Ministério da Ciência, Tecnologia e Inovação:

No cenário mundial contemporâneo, as empresas inovadoras são reconhecidamente os instrumentos fundamentais ao desenvolvimento sustentável, à geração de emprego e renda e à democratização de oportunidades. No entanto, a juventude, mesmo aqueles com acesso à educação superior, ainda tem como uma das principais estratégias a realização de concursos públicos (VALOR ECONÔMICO, 20/1/2012).

Resta claro que a lógica que enaltece o empreendedorismo em detrimento de empregos estáveis não tem em vista apenas a solução da emergencial crise de empregos no país, mas também atua no sentido de mudar a própria constituição de sua oferta. Busca-se, com o estímulo ao empreendedorismo, fazer crescer o número de trabalhadores autônomos que, sendo autossuficientes, não estariam respaldados por leis trabalhistas que preveem direitos como décimo terceiro, férias e aposentadoria. 
Para os defensores desse tipo de proposta, essa política corresponde às necessidades do mundo produtivo, especialmente à necessidade de evitar que os jovens se encaminhem por trajetórias profissionais semelhantes às de seus pais, ou seja, vinculadas ao mercado de trabalho formal, ao emprego formal assalariado, hoje consideradas sem futuro (DREWINSKI, 2009, p. 33).

\section{Conclusão}

Neste artigo procurei analisar alguns discursos sociais promotores daquilo que chamei de cultura empreendedora. A escolha de iniciar tal análise com a comparação de duas séries televisivas direcionadas ao público jovem e distantes entre si em quinze anos teve como objetivo ilustrar a rápida aculturação dos valores do empreendedorismo em nossa sociedade. Se em Confissões, como visto, valores e práticas empreendedores não são naturalmente apresentados na trama, o mesmo não pode ser dito da produção mais recente, Ger@l.com. Nesta última, é possível assistir à construção de subjetividades juvenis que são superprodutivas, autorresponsáveis e normatizadas pela alta performance. Enfim, subjetividades juvenis empreendedoras.

Os demais discursos analisados - de reportagens de revistas a leis e projetos educacionais - serviram, mesmo que de forma assistemática, para demonstrar o espraiamento dos valores empreendedores em nossa contemporânea sociedade. Tais discursos, ao evidenciar e saudar práticas juvenis empreendedoras, naturalizam a transferência de responsabilidade - de nível institucional a nível individual - pelo acesso às oportunidades de emprego e realização profissional. Justificando uma racionalidade de responsabilização pessoal, tais enunciações estariam coordenadas com lógicas particulares ao sistema neoliberal, no qual são positivadas ações individuais com vistas a conquistas, igualmente individuais, de sucesso, notoriedade e riqueza. Como consequência, a subjetividade jovem requerida e valorizada pela mídia neste início de século XXI - e aquela que, portanto, serve de exemplo aos demais - é a do jovem empreendedor: lucrativo como os "novos milionários da internet", de Época; inovador como o "menino prodígio da geração digital", de Veja e dinâmico como todos os personagens da série Ger@l.com.

Julia Salgado é jornalista e doutoranda na Escola de Comunicação da UFRJ; é mestre pela mesma escola juliasalgado@gmail.com 


\section{Referências}

BALL, S. J. Performatividade, privatização e o pós-estado do bem-estar. In: Educ. Soc., Campinas, vol. 25, n. 89, 2004, p. 1105-1126.

BOLTANSKI, L.; CHIAPELLO, E. O novo espírito do capitalismo. São Paulo: Martins Fontes, 2009.

BRASIL. Constituição. Constituição da República Federativa do Brasil. DF: Senado, 1998.

COSTA, S. Governamentalidade neoliberal, teoria do capital humano e empreendedorismo. In: Educação\&Realidade, vol. 34, n. 2, 2009, p. 171-186.

COULDRY, N. Reality TV, ou o teatro secreto do neoliberalismo. In: COUTINHO, E.; FREIRE FILHO, J.; PAIVA, R. (Org.) Mídia e poder. Rio de Janeiro: Mauad X, 2008.

DAVID, D. et ali. Aspectos pedagógicos no ensino do empreendedorismo. Anais. III Encontro Nacional de Empreendedorismo, Florianópolis, 2001.

DECRETO-LEI n. 4991. Rio do Sul, SC, 21/5/2010. Disponível em <http://www.leismunicipais.com. br/cgi-local/forpgs/showinglaw.pl>. Acesso em: 29 nov. 2010.

DOLABELA, F. Pedagogia Empreendedora. São Paulo: Ed. Cultura, 2003.

DREWINSKI, J. Empreendedorismo: o discurso pedagógico no contexto do agravamento do desemprego juvenil. (Tese de Doutorado em Educação). Universidade Federal do Paraná, Curitiba, 2009.

EHRENBERG, A. O culto da performance. São Paulo: Editora Ideias \& Letras, 2010.

FOUCAULT, M. O nascimento da biopolítica. São Paulo: Martins Fontes, 2008.

FREIRE FILHO, J. O poder em si mesmo: jornalismo de autoajuda e a construção da autoestima. In: Famecos, Porto Alegre, v. 18, n. 3, 2011, p. 717-745.

POCHMANN, M. Situação do jovem no mercado de trabalho no Brasil. São Paulo, 2007. Disponível em: <http://www.emater.mg.gov.br/doc/intranet/upload/TRANSFOR MAR_LEITURA/ situa\%C3\%A7\%C3\%A3o_do_jovem_no_mercado_de_trabalho.pdf $>$. Acesso em: 29 nov. 2010.

ROSE, N. The powers of freedom. Cambridge University Press, 1999. Inventing our selves. Cambridge University Press, 1998. 